\title{
Shen-Qi-Jie-Yu-Fang exerts effects on a rat model of postpartum depression by regulating inflammatory cytokines and $\mathrm{CD} 4^{+} \mathrm{CD} 25^{+}$regulatory $\mathrm{T}$ cells
}

This article was published in the following Dove Press journal:

Neuropsychiatric Disease and Treatment

15 April 2016

Number of times this article has been viewed

\author{
Jingya $\mathrm{Li}^{1, *}$ \\ Ruizhen Zhao',* \\ Xiaoli $\mathrm{Li}^{\prime}$ \\ Wenjun Sun' \\ Miao Qu' \\ Qisheng Tang' \\ Xinke Yang' \\ Shujing Zhang ${ }^{2}$ \\ 'Third Affiliated Hospital, ${ }^{2}$ School \\ of Basic Medical Sciences, Beijing \\ University of Chinese Medicine, \\ Beijing, People's Republic of China \\ *These authors contributed equally \\ to this work
}

Background: Shen-Qi-Jie-Yu-Fang (SJF) is composed of eight Chinese medicinal herbs. It is widely used in traditional Chinese medicine for treating postpartum depression (PPD). Previous studies have shown that SJF treats PPD through the neuroendocrine mechanism.

Aim: To further investigate the effect of SJF on the immune system, including the inflammatory response system and $\mathrm{CD}^{+} \mathrm{CD} 25^{+}$regulatory $\mathrm{T}\left(\mathrm{T}_{\text {reg }}\right)$ cells.

Materials and methods: Sprague Dawley rats were used to create an animal model of PPD by inducing hormone-simulated pregnancy followed by hormone withdrawal. After hormone withdrawal, the PPD rats were treated with SJF or fluoxetine for 1, 2, and 4 weeks. Levels of $\mathrm{T}_{\mathrm{reg}}$ cells in peripheral blood were measured by flow cytometry analysis. Serum interleukin (IL)-1 $\beta$ and IL- 6 were evaluated by enzyme-linked immunosorbent assay, and gene and protein expressions of IL-1 $\mathrm{R}_{\mathrm{I}}$, IL-6R $\alpha$, and gp130 in the hippocampus were observed by reverse-transcription polymerase chain reaction and Western blot.

Results: Serum IL- $1 \beta$ in PPD rats increased at 2 weeks and declined from then on, while serum IL-6 increased at 1, 2, and 4 weeks. Both IL-1 $\beta$ and IL- 6 were downregulated by SJF and fluoxetine. Changes in gene and protein expressions of IL-1 $\mathrm{R}_{\mathrm{I}}$ and gp130 in PPD rats were consistent with changes in serum IL-1 $\beta$, and were able to be regulated by SJF and fluoxetine. The levels of $\mathrm{T}_{\text {reg }}$ cells were negatively correlated with serum IL-1 $\beta$ and IL-6, and were decreased in PPD rats. The levels of $\mathrm{T}_{\text {reg }}$ cells were increased by SJF and fluoxetine.

Conclusion: Dysfunction of proinflammatory cytokines and $\mathrm{T}_{\text {regs }}$ in different stages of PPD was attenuated by SJF and fluoxetine through the modulation of serum concentrations of IL-1 $\beta$ and IL-6, expressions of IL- $1 \mathrm{R}_{\mathrm{I}}$, and gp130 in the hippocampus, and $\mathrm{CD} 4^{+} \mathrm{CD} 25^{+} \mathrm{T}_{\text {reg }}$ cells in peripheral blood.

Keywords: postpartum depression, inflammatory cytokines, antidepressant drugs, Chinese herbal medicine, shenqi jieyu fang, animal model

\section{Introduction}

Postpartum depression (PPD) is a mood disorder with a high prevalence. ${ }^{1}$ It is not only a public health issue because of the risk of disability or even death for the mother but also impacts the infant's cognitive and behavioral development. ${ }^{2}$ PPD is considered a major depressive disorder in the Diagnostic and Statistical Manual of Mental Disorders, fifth edition. The pathomechanism of PPD is complex and remains unclear, though the nervous, endocrine, and immune systems in combination appear to be involved. Studies have also shown that the hippocampus, which controls mood, is likely involved and that estrogen induces epigenetic changes in its cells. ${ }^{3}$ The sex hormones may also be playing an important role in PPD, due to their physiologic effects. Serum levels of progesterone,
Correspondence: Qisheng Tang

Third Affiliated Hospital,

Beijing University of Chinese

Medicine, 5I Anwai Xiaoguan,

Chao Yang, Beijing 100029,

People's Republic of China

Tel +8610 52075206

Email tangqishengbucm@।26.com (c) (1) (8) 2016 Li et al. This work is published and licensed by Dove Medical Press Limited. The full terms of this license are available at https://www.dovepress.com/terms.php BY NC and incorporate the Creative Commons Attribution - Non Commercial (unported, v3.0) License (http://creativecommons.org/licenses/by-nc/3.0/). By accessing the work you
hereby accept the Terms. Non-commercial uses of the work are permitted without any further permission from Dove Medical Press Limited, provided the work is properly attributed. For permission for commercial use of this work, please see paragraphs 4.2 and 5 of our Terms (https://www.dovepress.com/terms.php). 
estrogen, cortisol, testosterone, and corticotropin-releasing hormone increase during pregnancy and then drastically diminish at parturition. ${ }^{4}$ These hormones interact with the immune system and the hypothalamic-pituitary-adrenal (HPA) axis, ${ }^{5}$ and their sudden decline may contribute to the mechanism of PPD.,7

PPD is closely linked to the immune system through activation of the inflammatory response. Maes et $\mathrm{al}^{8}$ first documented that mothers with PPD had higher levels of inflammation than those without PPD, indicating that similarly to major depression, inflammation is also involved in the pathogenesis of PPD. Serum concentrations of IL-6, IL-1RA, and leukemia inhibitory factor receptor alpha increase in the early puerperium, and correlate with anxiety and depressive symptoms. ${ }^{8}$ Activation of IL-6 and leukemia inhibitory factor receptor alpha are found to be related to an increased catabolism of tryptophan into kynurenine, and are suspected to be part of the pathogenesis of PPD. ${ }^{9}$ Boufidou et $\mathrm{al}^{10}$ also discovered a positive correlation between levels of IL-6 in cerebrospinal fluid and PPD.

Activation of the T-cell system has been shown to be involved in susceptibility to mood disorder. ${ }^{11} \mathrm{CD} 4+\mathrm{CD} 25^{+}$ regulatory $\mathrm{T}\left(\mathrm{T}_{\text {reg }}\right)$ cells are a subset of $\mathrm{CD}^{+} \mathrm{T}$-helper cells, and are key to restraining excessive T-cell responses. Animal and clinical studies on the immunologic role that $\mathrm{CD} 4^{+} \mathrm{CD} 25^{+} \mathrm{T}_{\text {reg }}$ cells play in PPD are few, and the results of these studies are inconsistent. Kim et $\mathrm{al}^{12}$ found that the stressed control group mice had significantly decreased $\mathrm{CD} 4^{+} \mathrm{CD} 25^{+} \mathrm{T}_{\text {reg }}$-cell population when compared with the unstressed control group, and mice with anti-CD25 antibody-mediated depletion of $\mathrm{T}_{\text {reg }}$ cells displayed a decreased 5-hydroxytryptamine (5-HT) level within the hippocampus. A previous study of ours had also found decreased levels of $\mathrm{CD} 4{ }^{+} \mathrm{CD} 25^{+} \mathrm{T}_{\text {reg }}$ cells in a rat model of PPD. ${ }^{13}$ However, Krause et $\mathrm{al}^{14}$ found that levels of $\mathrm{CD}^{+} \mathrm{CD} 25^{+} \mathrm{T}_{\text {reg }}$ cells were significantly increased in prenatal and postnatal mothers who had postnatal depressive symptoms, contradicting the results of the former two studies. Several cytokines can interfere with the differentiation of $\mathrm{T}_{\text {reg }}$ cells. For example, the proinflammatory cytokine IL-6 inhibits transforming growth factor beta (TGF $\beta$ )-induced $\mathrm{T}_{\text {reg }}$ differentiation. ${ }^{15}$ However, $\mathrm{T}_{\text {reg }}$ cells can also suppress the development of chronic inflammatory diseases, such as lupus, rheumatoid arthritis, and multiple sclerosis, through different mechanisms. ${ }^{16}$ Furthermore, IL-6 and tumor necrosis factor- $\alpha$ have been found to be upregulated by $\mathrm{CD} 4^{+} \mathrm{CD} 25^{+} \mathrm{T}_{\text {reg }}$-cell depletion. ${ }^{12}$ Therefore, the involvement of $\mathrm{T}_{\text {reg }}$ cells has not yet been elucidated in PPD, although, fundamentally, there appears to be an interaction between $\mathrm{T}_{\text {reg }}$ cells and cytokines triggering the symptoms of PPD.

Shen-Qi-Jie-Yu-Fang (SJF) is a traditional Chinese herbal prescription that is widely used in the People's Republic of
China (PRC) for treating PPD. Our previous work on a rat model of PPD found that SJF improved behavioral performance for increased sucrose consumption, horizontal and vertical scores, and decreased immobility time, and was able to accelerate the recovery of pathologic injury in rat brain tissue. ${ }^{17-20}$ The mechanism of action of SJF is related to the HPA axis, HP-gonadal axis, and immune system. We found that, with the HPA axis, SJF can upregulate monoamine neurotransmitters, such as 5-HT, norepinephrine, and dopamine in the hippocampus and hypothalamus. ${ }^{18}$ The effects of SJF on the HP-gonadal axis (also in PPD rats) were upregulation of estrogen and downregulation of progesterone to correct hormonal imbalance, ${ }^{19}$ as well as upregulation of estrogen receptor expression. ${ }^{20} \mathrm{SJF}$ has also been found to exert a regulating effect on the expression of $\mathrm{CD}^{+}, \mathrm{CD}^{+}$, and $\mathrm{CD}^{+} \mathrm{T}$ cells by organs of the immune system. ${ }^{13}$ Moreover, selective serotonin-reuptake inhibitor (SSRI) antidepressants have been found to be anti-inflammatory, which may explain their effectiveness in treating PPD. ${ }^{21}$ Some herbs, such as Siberian ginseng (Acanthopanax senticosus [Rupr et Maxim] Harms), ${ }^{22}$ wild turmeric root (Curcuma aromatica Salisb), ${ }^{23}$ astragalus root (Astragalus membranaceus [Fisch] Bunge), ${ }^{24}$ and salvia root (Salviae miltiorrhizae Bunge), ${ }^{24}$ have also been shown to have anti-inflammatory effects and relieve depressive symptoms. SJF also contains some herbs that possess anti-inflammatory properties, which we hypothesize may be its mechanism for treating PPD (Figure 1).

Given that the inflammatory response system and $\mathrm{T}_{\text {regs }}$ have been shown to be linked to PPD, the aim of this study was to investigate the mechanism of SJF for treating PPD by utilizing processes involving $\mathrm{T}_{\text {regs }}$ and proinflammatory cytokines. After intervention with SJF, we observed changes in the concentrations of IL- 6 and IL- $1 \beta$ in the serum, as well as changes in the levels of IL-6R $\alpha$, gp 130, and IL-1 $\mathrm{R}_{\mathrm{I}}$ in the brain, in the level of $\mathrm{T}_{\text {reg }}$ cells in the blood.

\section{Materials and methods Ethics statement}

This study was approved by the Beijing Institute of Animal Ethics Committee (Beijing, People's Republic of China). The procedures used were in accordance with the Guidelines for Animal Experimentation of Beijing University of Chinese Medicine (Beijing, People's Republic of China). All effort was made to keep the number of animals used in this study to a minimum and to minimize their suffering. All animalhandling procedures were performed according to the Guide for the Care and Use of Laboratory Animals of the National Institutes of Health and followed the guidelines of the Animal Welfare Act. 


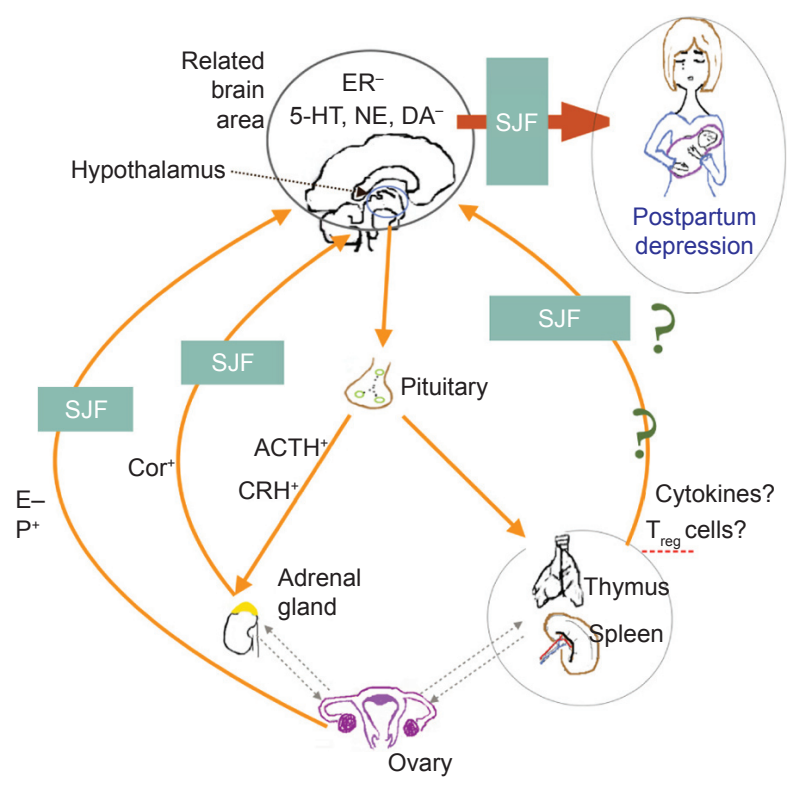

Figure I SJF's mechanism of action on PPD.

Abbreviations: $\mathrm{HT}$, hydroxytryptamine; NE, norepinephrine; DA, dopamine; SJF, ShenQi-Jie-Yu-Fang; E, estrogen; P, progesterone; Cor, cortisol; ACTH, adrenocorticotropic hormone; $\mathrm{CRH}$, corticotropin-releasing hormone; $\mathrm{T}_{\text {reg }}$, regulatory $\mathrm{T}$.

\section{Preparation of SJF decoction and fluoxetine}

SJF is made up of eight Chinese medicinal herbs of varying amounts (Table 1). The granules containing SJF were sourced from Tcmages Pharmaceutical (Beijing, PRC) and authenticated by the Department of Pharmaceutical Preparation of the Third Affiliated Hospital of Beijing University of Chinese Medicine, where voucher specimens were deposited. Two packets of SJF granules (containing 107 $\mathrm{g}$ of crude drug, equivalent to an adult dose for 1 day) were mixed and dissolved in $85.6 \mathrm{~mL}$ of double-distilled water to a concentration of $1.25 \mathrm{~g} / \mathrm{mL}$. The solution was stored at $4^{\circ} \mathrm{C}$, and heated before gavage to the experimental rats. Fluoxetine hydrochloride (2090A; Eli Lilly and Company, Indianapolis, IN, USA) was dissolved in distilled water to a concentration of $0.25 \mathrm{mg} / \mathrm{mL}$. The gavage volume was calculated as rat weight (g) multiplied by $0.25 \mathrm{mg} / 100 \mathrm{~g}$.

\section{Animals}

A total of 100 female Sprague Dawley rats (Vital River Laboratory, Beijing, PRC) weighing $200 \pm 10 \mathrm{~g}$ were housed in 20 cages (five per cage) in a controlled environment of $22^{\circ} \mathrm{C} \pm 2{ }^{\circ} \mathrm{C}$ 12-hour light/dark cycle, with ad libitum access to standard rat chow and water. The study flowchart is shown in Figure 2.

\section{HSP procedure and intervention Groups and ovariectomy}

After 7 days of adaptive feeding, all the rats were subjected to the open field test (OFT). Ten rats whose total OFT scores were too high $(>150)$ or too low $(<30)$ were excluded, and the remaining 90 rats were randomly divided into five groups: normal group (naïve + double-distilled water, $\mathrm{n}=18$ ), sham-operated group (ovariectomized control + double-distilled water, $\mathrm{n}=18$ ), hormone-simulated pregnancy (HSP) group (HSP + double-distilled water, $\mathrm{n}=18$ ), $\mathrm{SJF}$ group (HSP $+\mathrm{SJF}, \mathrm{n}=18)$, and fluoxetine group (HSP + fluoxetine, $\mathrm{n}=18$ ). All the rats in the latter three groups were ovariectomized bilaterally under chloral hydrate anesthesia $(10 \%, 0.4 \mathrm{~mL} / 100 \mathrm{~g})$, using an aseptic technique, and allowed 7 days of recovery. Rats in the sham-operated group were sham ovariectomized bilaterally, while rats in the normal group were not subjected to any intervention.

\section{HSP}

Rats in the three ovariectomized groups underwent vaginal smear testing to confirm complete ovariectomy. Ovariectomized rats then received daily subcutaneous injections of the hormones estradiol benzoate (EB; Hangzhou Animal Medicine Factory, Hangzhou, PRC) and progesterone (Shanghai General Pharmaceutical, Shanghai, PRC) to simulate the 23-day rat gestational period. During days 1-16, all the three ovariectomized groups were administered a oncedaily low dose of EB $(2.5 \mu \mathrm{g})$ combined with a high dose of progesterone $(4 \mathrm{mg})$ dissolved in $0.1 \mathrm{~mL}$ sesame oil. On days $17-23$, the rats received only a high dose of $\mathrm{EB}(50 \mu \mathrm{g})$. On day 24 , the injections were stopped so that hormone

Table I Herbal ingredients in Shen-Qi-jie-Yu-Fang and their amounts

\begin{tabular}{ll}
\hline Common name & Latin botanical name \\
\hline Astragalus root & Astragalus membranaceus (Fisch) Bunge \\
Wild turmeric root & Curcuma aromatica Salisb \\
Sour jujube seed & Ziziphus jujuba var spinosa (Bunge) \\
& Hu ex HF Chow \\
Cornus fruit & Cornus officinalis Sieb et Zucc (Cornaceae) \\
Codonopsis root & Codonopsis pilosula (Franch) Nannf \\
Aged tangerine peel & Citrus reticulata Blanco \\
Citron & Citrus medica L \\
Angelica root & Angelica sinensis (Oliv) Diels \\
\hline
\end{tabular}




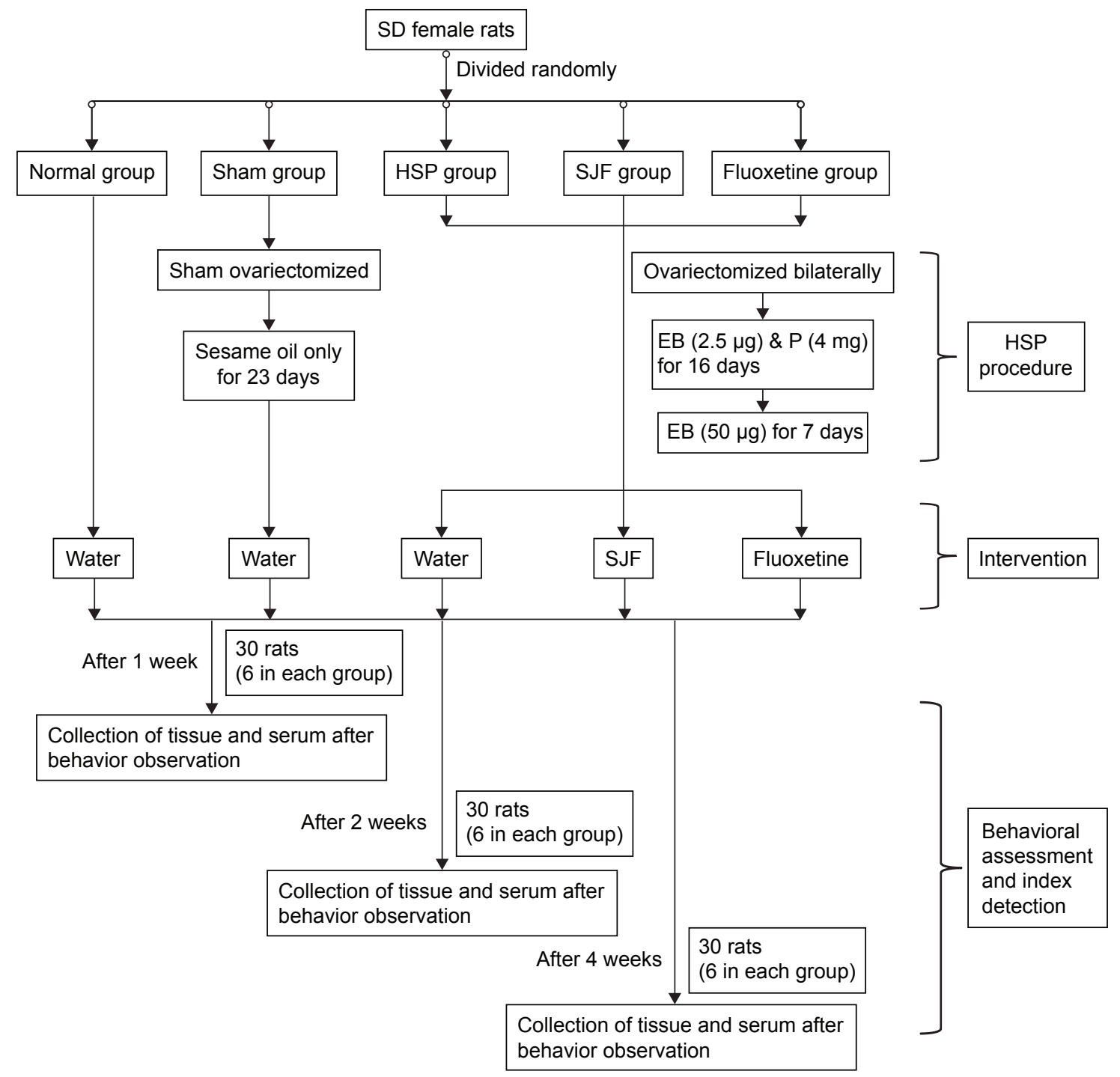

Figure 2 Study flowchart.

Abbreviations: SD, Sprague Dawley; Sham, sham-operated group; HSP, hormone-simulated pregnancy; SJF, Shen-Qi-Jie-Yu-Fang; EB, estradiol benzoate; P, progesterone.

withdrawal could be started. Rats in the sham-operated group were administered $0.1 \mathrm{~mL}$ of sesame oil daily for 23 days.

\section{Intervention}

After the 23-day injection period, all the five groups were started on the intervention. Rats in the normal group, sham-operated group, and HSP group were given $2 \mathrm{~mL}$ double-distilled water, rats in the SJF group were given $2 \mathrm{~mL}$ of SJF, and rats in the fluoxetine group were given $2 \mathrm{~mL}$ of fluoxetine. Double-distilled water, SJF, and fluoxetine were administered by gavage daily for 1,2 , and 4 weeks, respectively.

\section{Behavioral assessments}

Depression behavioral testing, including the OFT, sucrose consumption, and forced swim test (FST) were conducted at weeks 1, 2, and 4 after HSP modeling was completed. At 24 hours after the last behavior test, all the rats were killed by decapitation, and blood and hippocampi of rats from all the five groups were collected.

\section{OFT}

The $\mathrm{OF}$ apparatus consisted of a square arena $(80 \times 80 \times 40 \mathrm{~cm})$, with a black surface covering the inside walls. The floor was divided into 25 squares marked by white lines. Animal cages were put in the testing room 1 hour before the test to allow them to acclimatize to the experimental environment. Before each animal was tested, the floor of the apparatus was wiped with alcohol. During testing, each rat was placed at the center of the apparatus and then the tester left the room. The numbers of horizontal and vertical movements were recorded by a video camera for 5 minutes and counted by testers. 


\section{FST}

The rats were subjected to two trials, during which they were forced to swim in a transparent glass cylinder (height $60 \mathrm{~cm}$, diameter $25 \mathrm{~cm}$ ) filled with $35 \mathrm{~cm}$ of water. The first trial lasted 15 minutes. After 24 hours, a second 5-minute trial was performed. Immobility was measured in the second test. Immobility was defined as a rat not making any active movements, with at least one hind paw pressed against the bottom or the wall of the cylinder.

\section{Sucrose consumption}

This test was administered as described previously. ${ }^{17}$ Prior to testing, all the rats were deprived of drinking water for 24 hours in their home cages. The following day, all the rats were given a bottle of $1 \%$ sucrose solution and allowed to drink freely for 1 hour. The sugar water intake in the test equaled the weight of the bottle before the test minus the weight of the bottle after the test.

\section{Tissue and blood collection}

The rats were anesthetized with chloral hydrate $(10 \%$, $0.4 \mathrm{~mL} / 100 \mathrm{~g}$ ). Blood was collected from the abdominal aorta into tubes with a clot activator or heparin sodium anticoagulant. Tubes with the clot activator were allowed to stand for 4 hours at $4^{\circ} \mathrm{C}$, and were centrifuged at $4^{\circ} \mathrm{C}$, $2,835 \mathrm{~g}$ for 15 minutes to obtain the serum. Aliquots were stored at $-80^{\circ} \mathrm{C}$ until assayed for concentrations of IL- $1 \beta$ and IL-6. Blood in heparin sodium tubes underwent flow cytometry analysis immediately after collection.

Right after blood collection, the anesthetized animals were killed by cervical dislocation. The brain of each rat was carefully removed from the skull and the hippocampus integrally isolated for storage at $-80^{\circ} \mathrm{C}$ before being assayed for gene IL-1RI, IL-6R $\alpha$, and gp130 and protein expression of IL-1RI, IL-6R $\alpha$, and gp130.

\section{Flow cytometry analysis}

After the behavioral tests, abdominal arterial blood from the anesthetized rats was collected into heparin sodium-coated tubes. Whole peripheral blood mononuclear cells were isolated by lymphocyte separation solution (Tianjin Haoyang Biological Manufacture, Tianjin, PRC) and counted to $1 \times 10^{6}$ cells $/ 100 \mu \mathrm{L}$. Peripheral blood mononuclear cells $(100 \mu \mathrm{L})$ were stained with $2 \mu \mathrm{L}$ of PerCP-CD4 (eBioscience, San Diego, CA, USA), fluorescein isothiocyanate-CD25, and Foxp3 with a fix/perm buffer set (BioLegend, San Diego, CA, USA) according to the manufacturer's instructions. Fluorescence-activated cell sorting data were acquired using a FACSCalibur platform (BD Biosciences, San Jose,
CA, USA) and analyzed using CellQuest Pro software (BD Biosciences).

\section{Enzyme-linked immunosorbent assay}

Plasma levels of IL-1 $\beta$ and IL-6 were determined using commercially available enzyme-linked immunosorbentassay kits (MultiSciences Biotech, Hangzhou, PRC) that had been validated previously for use. ${ }^{25,26}$ Inter- and intra-assay coefficients of variation for IL- $1 \beta$ were $5.1 \%$ and $6.7 \%$ and for IL-6 were $9.1 \%$ and $7.7 \%$, respectively. Minimum detection limits for the assays were $1.42 \mathrm{pg} / \mathrm{mL}$ for IL- $1 \beta$ and $2.57 \mathrm{pg} / \mathrm{mL}$ for IL-6. The antibodies had negligible cross-reactivity $(<0.001 \%)$ with similar mammalian peptides.

\section{Western blot analysis}

The hippocampus tissues were extracted from the five rat groups and ground using a glass mortar and pestle with freshly prepared radio immunoprecipitation assay (RIPA) and phenylmethylsulfonyl fluoride protease inhibitor (Solarbio Science and Technology, Beijing, PRC), and the homogenate was centrifuged at $12,000 \mathrm{~g}$ for 15 minutes at $4^{\circ} \mathrm{C}$ to remove cell debris. Protein concentrations were analyzed using a bicinchoninic acid protein-assay kit (ApplyGen Technologies, Beijing, PRC). Proteins $(100 \mu \mathrm{g})$ were resolved by polyacrylamide gel at a constant voltage of 120 $\mathrm{V}$ for 100 minutes and transferred to an Immobilon-P polyvinylidene difluoride transfer membrane (Merck Millipore, Billerica, MA, USA) for electrophoresis with a constant voltage of $100 \mathrm{~V}$ for 70 minutes using a PowerPac universal power supply (Bio-Rad, Hercules, CA, USA). The membranes were immersed for 2 hours in a wash buffer ( $50 \mathrm{mM}$ Tris- $\mathrm{HCl}$, $150 \mathrm{mM} \mathrm{NaCl}$, and $0.1 \%$ Tween 20 at $\mathrm{pH} 7.5$ ) containing $5 \%$ fat-free milk. The membranes were then incubated with different primary antibodies (1:500 monoclonal rabbit anti-IL-1 R [Santa Cruz Biotechnology, Dallas, TX, USA], 1:150 monoclonal rabbit IL-6R $\alpha$ [LifeSpan BioSciences, Seattle, WA, USA], 1:2,000 monoclonal rabbit gp130 [Cell Signaling Technology, Danvers, MA, USA]) for 1.5 hours at room temperature and then overnight at $4^{\circ} \mathrm{C}$. The following day, the membranes were washed and incubated with the appropriate horseradish peroxidase-labeled secondary antibody (1:2,000; Beijing Biosynthesis Biotechnology, Beijing, PRC) for 1 hour at room temperature, followed by detection with SuperSignal West Femto substrate (Thermo Fisher Scientific, Waltham, MA, USA). To ensure that equal quantities were loaded in each lane, the membranes were blotted with anti- $\beta$-actin antibody $(1: 2,000$; Beijing Biosynthesis Biotechnology). Immunoreactive bands were quantified by 
scanning densitometry (Quantity One software; Bio-Rad), and the density of each band was normalized to that of its own $\beta$-actin. Biological variability was avoided by using extracts from three separate preparations. Technical variability was avoided by performing each analysis in triplicate.

\section{Reverse-transcription polymerase chain reaction}

Total RNA was extracted from the hippocampus tissues of rats in all five groups on days 7, 14, and 21 after initiation of SJF intervention using Trizol reagent (Thermo Fisher Scientific) and absorbances at $260 \mathrm{~nm}$ and $280 \mathrm{~nm}$ were determined to estimate the amount of RNA. The extracted RNA was then stored at $-80^{\circ} \mathrm{C}$. Reverse-transcription polymerase chain reaction (RT-PCR) was determined using a Dynamo Flash SYBR Green qPCR kit (Thermo Fisher Scientific) according to the manufacturer's instructions. The following primer pairs were used: IL-1R - I , 5'-CGCACGTCCTACACATACCA-3', IL-1 R - R, 5'-CATTCCGTGGGCTCATAATC-3';

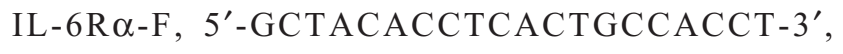
IL-6R $\alpha-\mathrm{R}, 5^{\prime}$-ACTCGCTTCAATCACAGCATT-3'; Gp130-F， 5'-GACACCGCCATCTAAACCTG-3'; Gp130-R, 5'-ACAGTGCCATCTTCTTGCTG-3'; actin-F, 5'-TGTCACCAACTGGGACGATA-3', actin-R, 5'-GGGGTGTTGAAGGTCTCAAA-3'.

RT-PCR was performed with the StepOnePlus RT-0PCR system (Thermo Fisher Scientific). The cycling conditions were set to an initial denaturation at $95^{\circ} \mathrm{C}$ for 10 minutes, followed by 40 cycles with denaturation at $95^{\circ} \mathrm{C}$ for 5 seconds, annealing at $60^{\circ} \mathrm{C}$ for 15 seconds, and elongation at $95^{\circ} \mathrm{C}$ for 15 seconds. Specificity of the PCR products was validated by performing melting-curve analyses. The reactions were performed in triplicate for each of six separate samples in each group. Comparative $\mathrm{C}_{\mathrm{T}}$ was used to obtain quantitative data of relative gene expressions, according to the manufacturer's instructions. Values for each gene were normalized to expression levels of $\beta$-actin.

\section{Statistical analysis}

Data were evaluated with SPSS 20.0 software (IBM, Armonk, NY, USA). The numbers of horizontal and vertical movements measured in the OFT; immobile time measured in the FST; sucrose consumption; serum levels of IL-1 $\beta$ and IL-6; gene and protein expression of IL-1R, IL-6R $\alpha$, and gp130 in the hippocampus; and $\mathrm{T}_{\text {reg }}$ cells in the whole blood of the five groups were each subjected to one way ANOVA analysis of variance. A comparison of the serum levels of IL-1 $\beta$ and IL-6 and gene expression of IL-1R, IL-6R $\alpha$, and gp130 in the hippocampus between three time points (1, 2, and 4 weeks) were subjected to two dependent $t$-tests. Correlations between $\mathrm{T}_{\text {regs }}$ and serum levels of IL-1 $\beta$ and IL- 6 were used for correlation analysis. All statistical tests were two-sided, with 95\% confidence intervals. Bartlett's test of homogeneity of variance was conducted on all behaviors.

\section{Results}

\section{Depressive behavior in HSP rat model} was attenuated in SJF and fluoxetine rats

Numbers of horizontal and vertical movements in the OFT in the HSP group were significantly lower than in the normal, sham, SJF, and fluoxetine groups 1 week after the initiation of intervention $\left(F_{4,35}=13.78, F_{4,35}=9.27\right.$, respectively; $\left.P<0.01\right)$, at 2 weeks $\left(F_{4,35}=6.05, F_{4,35}=4.42\right.$, respectively; $\left.P<0.05\right)$, and at 4 weeks $\left(F_{4,35}=10.75, F_{4,35}=7.63\right.$, respectively; $\left.P<0.01\right)$ (Figure $3 \mathrm{~A}$ and $\mathrm{B}$ ).

Time of immobility in the FST in the HSP group was markedly higher than the normal and sham-operated groups at 1,2 , and 4 weeks following intervention $\left(F_{4,25}=13.06\right.$, $F_{4,25}=5.57$, and $F_{4,25}=8.61$, respectively; $\left.P<0.01\right)$. There was no difference in immobility time between the SJF, fluoxetine, and HSP groups at 1 week following intervention $(P>0.05)$. At 2 weeks, immobility time in the SJF group was significantly lower than in the HSP group $(P<0.05)$, and at 4 weeks both SJF and fluoxetine groups exhibited markedly decreased immobility compared with the HSP group $(P<0.01)$ (Figure 3C).

Sucrose intake in the HSP group was definitely lower than the normal and sham-operated groups at 1, 2, and 4 weeks after intervention $\left(F_{4,25}=4.16, F_{4,25}=2.83\right.$ and $F_{4,25}=3.58$, respectively; $P<0.05$ ). There was no difference in sucrose intake between the SJF, fluoxetine, and HSP groups at 1 week after the start of intervention $(P>0.05)$, but by 2 and 4 weeks, rats in the SJF and fluoxetine groups consumed more sucrose than the HSP group $(P<0.05)$ (Figure 3D).

\section{Serum IL-I $\beta$ increased and then decreased in PPD rats, and was attenuated by SJF and fluoxetine}

Serum levels of IL-1 $\beta$ in the HSP, SJF, and fluoxetine groups were markedly higher than the normal and sham groups at 1 week after the start of intervention $\left(F_{4,25}=5.78, P<0.01\right)$ but lower than the normal and sham groups at 4 weeks ( $F_{4,25}=6.24, P<0.01$ and $F_{4,25}=3.49, P<0.05$, respectively). The SJF and fluoxetine groups exhibited lower serum levels of IL-1 $\beta$ than the HSP group at 1 week $(P<0.05)$. There was no difference between the SJF and fluoxetine groups $(P>0.05)$. Comparison across groups found that serum levels 
A

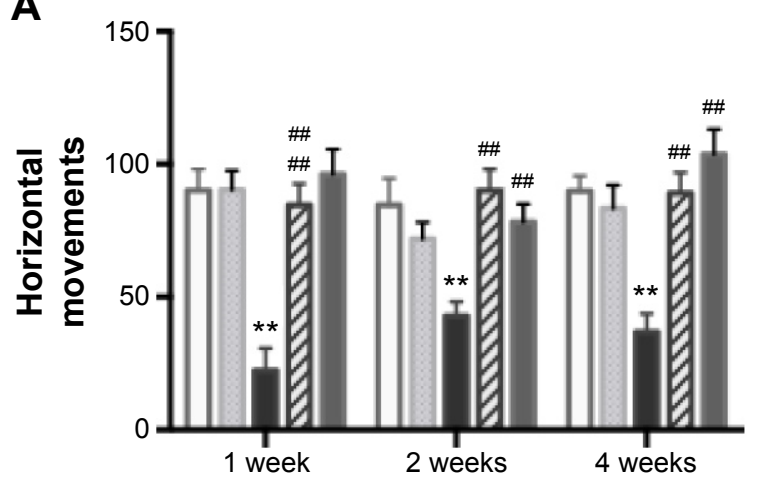

C

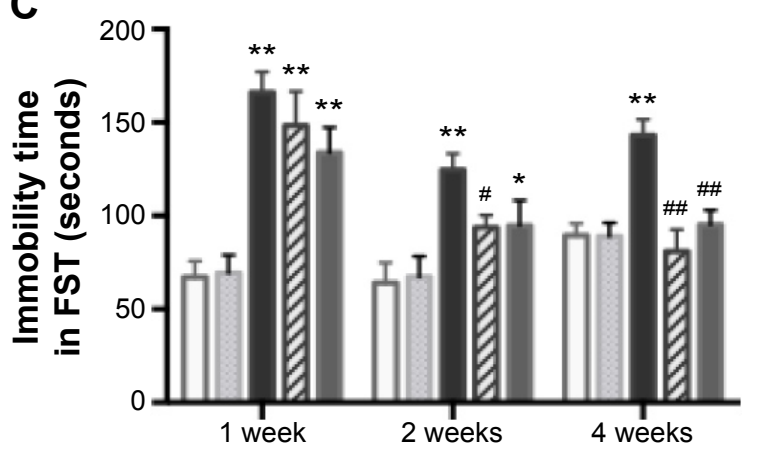

B



D

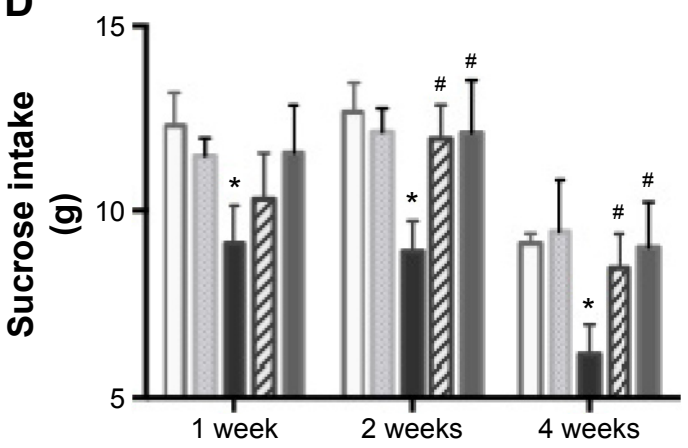

Normal group

HSP

ZZ SJF Fluoxetine

Figure 3 Effect of SJF on behavior performance of PPD rats with HSP withdrawal.

Notes: Scores (mean \pm SEM) of horizontal movements $(\mathbf{A})$, vertical movements $(\mathbf{B})$, time (mean \pm SEM) of immobility $(\mathbf{C})$, and consumption (mean \pm SEM) of sucrose (D) in normal, sham-operated, HSP, SJF, and fluoxetine groups at weeks I, 2, and 4 after HSP phase ( $\mathrm{n}=6$ per group). ${ }^{* * P}<0.0 \mathrm{I}$, ${ }^{*} \mathrm{P}<0.05$ vs normal and sham rats; $\mathrm{N} P<0.0 \mathrm{I}$, ${ }^{\#} P<0.05$ vs PPD rats. A one way ANOVA was performed to obtain these results.

Abbreviations: SJF, Shen-Qi-Jie-Yu-Fang; PPD, postpartum depression; HSP, hormone-simulated pregnancy; SEM, standard error of mean; FST, forced swim test.

of IL-1 $\beta$ in the HSP, SJF, and fluoxetine groups displayed a downward trend $(P<0.01)$, while the normal and sham groups exhibited stable serum levels of IL-1 $\beta$ (Figure 4A).

\section{Serum IL-6 remained increased in PPD rats and was diminished by SJF and fluoxetine}

IL-6 in the HSP group remained higher than the normal and sham-operated groups at 1,2 , and 4 weeks $\left(F_{4,25}=3.09\right.$, $\left.F_{4,25}=2.78, F_{4,25}=4.35, P<0.05\right)$, while the SJF and fluoxetine groups exhibited lower levels of IL-6 than the HSP model group at 2 and 4 weeks ( $P<0.05$ and $P<0.01$, respectively). In addition, the fluoxetine group displayed a lower level of IL-6 at 1 week $(P<0.05)$ (Figure 4B).

\section{Gene and protein expression of IL-I $R_{1}$ and gpl 30 increased and then decreased in the hippocampi of PPD rats}

Gene expression of IL-1 $\mathrm{R}_{1}$ in the HSP group was significantly higher than the normal and sham groups at 1 and 2 weeks after the start of intervention $\left(F_{4,25}=2.85\right.$ and $F_{4,25}=2.95$, respectively; $P<0.05)$, but lower than the normal and sham groups at 4 weeks $\left(F_{4,25}=5.28, P<0.01\right)$. The SJF and fluoxetine groups did not exhibit any difference compared with the normal group at 1,2 , or 4 weeks $(P>0.05)$. There was no difference between the SJF and fluoxetine groups at 1,2, or 4 weeks $(P>0.05)$. Gene expression of IL- $1 \mathrm{R}_{\mathrm{I}}$ in the HSP group showed a downward trend $(P<0.01)$, while expressions in the four other groups remained stable throughout the intervention period (Figure 5A).

Protein expression of IL- $1 \mathrm{R}_{\mathrm{I}}$ in the HSP group was higher than all the other groups at 1 and 2 weeks after the start of intervention $\left(F_{4,25}=10.69\right.$ and $F_{4,25}=3.86$, respectively; $P<0.01)$ and lower than all the other groups at 4 weeks $\left(F_{4,25}=5.121, P>0.01\right)$. There was no difference in protein expression levels of IL- $1 \mathrm{R}_{\mathrm{I}}$ in the SJF and fluoxetine groups when compared with the normal and shamoperated groups at 1,2 , or 4 weeks $(P>0.05)$. There was no difference either between the SJF and fluoxetine groups $(P>0.05)$ (Figure 6).

There was no difference in IL-6R $\alpha$ gene expression between the HSP group and the normal, sham-operated, 


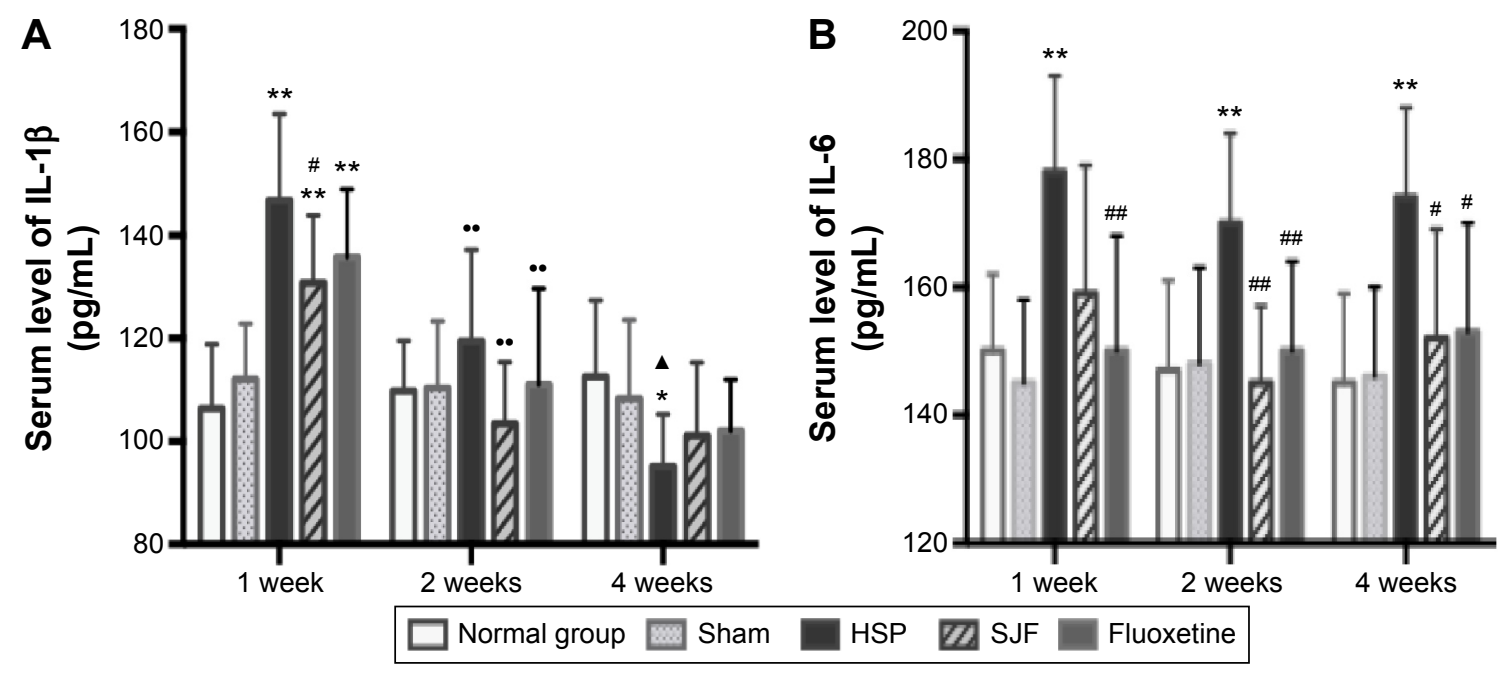

Figure 4 Effect of SJF on serum level of IL-I $\beta$ and IL-6 of PPD rats with HSP withdrawal.

Notes: Serum concentration (mean \pm SEM) of IL-I $\beta(A)$ and IL-6 (B) in normal, sham-operated, HSP, SJF, and fluoxetine groups at weeks I, 2 , and 4 after HSP phase ( $n=6$ per group). ${ }^{*} P P<0.01,{ }^{*} P<0.05$ vs normal and sham rats; ${ }^{*} P<0.05$, ${ }^{\# P} P<0.01$ vs $P P D$ rats; ${ }^{*} P<0.0$ I vs I week, ${ }^{\wedge} P<0.05$ vs 2 weeks.

Abbreviations: IL, interleukin; SJF, Shen-Qi-Jie-Yu-Fang; PPD, postpartum depression; HSP, hormone-simulated pregnancy; SEM, standard error of mean.

SJF, and fluoxetine groups at 1, 2, or 4 weeks (Figure 5B). There was no difference either in protein expression of IL-6R $\alpha$ among the five groups at 1,2 , or 4 weeks $\left(F_{4,25}=0.82\right.$, $P>0.05$ ) (Figure 6).

Similar to changes in $\mathrm{IL}-1 \mathrm{R}_{\mathrm{I}}$ expression, gp130 gene expression in the HSP group was significantly higher than the normal and sham groups at 1 and 2 weeks after the start of intervention $\left(F_{4,25}=2.88, P<0.05\right)$, but was lower than the normal and sham groups at 4 weeks $\left(F_{4,25}=3.396, P<0.05\right)$. There was no difference in levels of gp130 gene expression in the SJF and fluoxetine groups when compared with the normal group at 1,2 , or 4 weeks $(P>0.05)$. Gene expression of gp130 between the SJF and the fluoxetine group at 1,2 , and 4 weeks $(P>0.05)$ did not differ. Gene expression

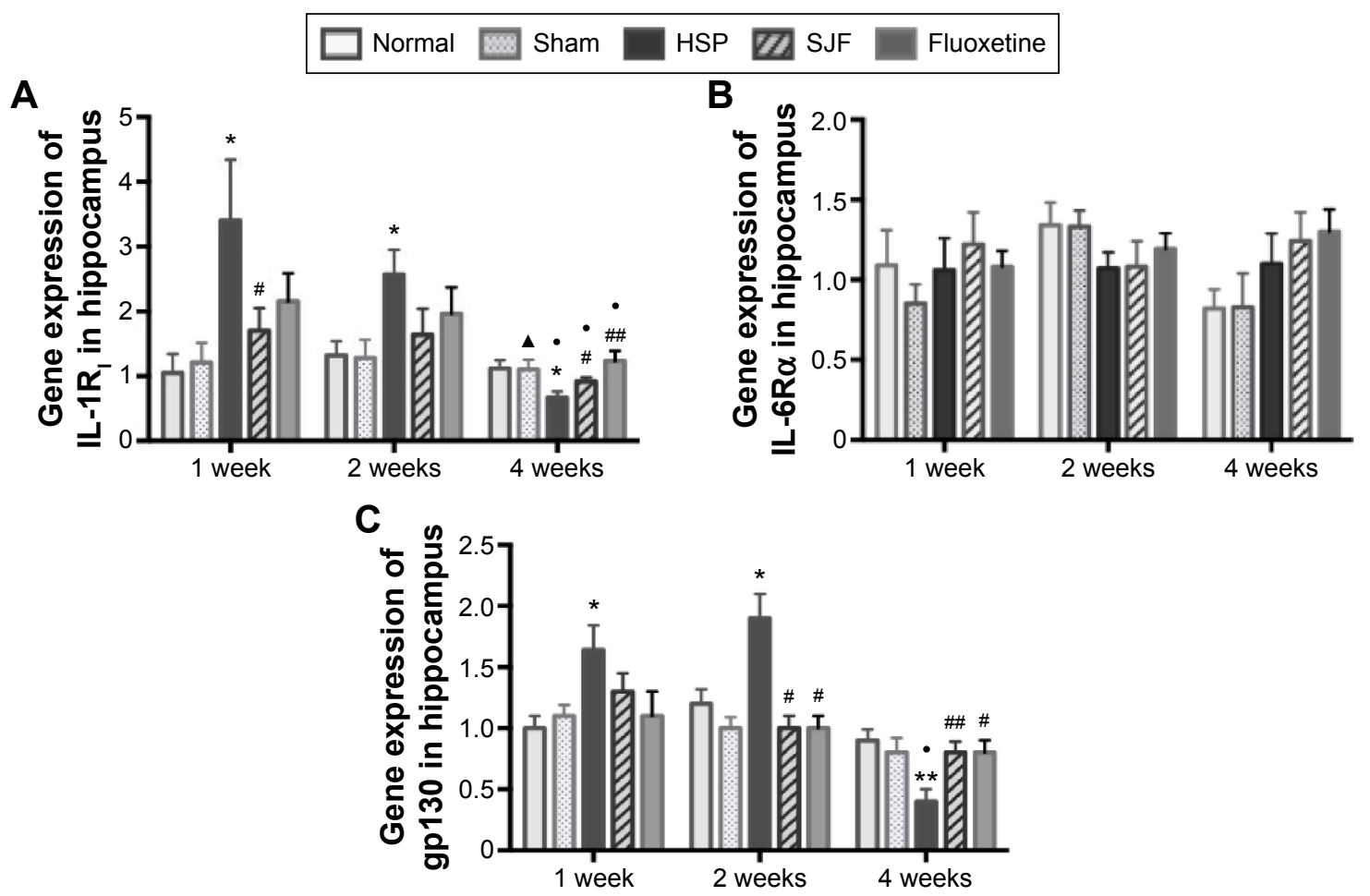

Figure 5 Effect of SJF on gene expression of IL-IR, gP I 30, and IL-6R $\alpha$ of PPD rats with HSP withdrawal.

Notes: Gene expression (mean \pm SEM) of IL-IR, gPI30, and IL-6R $\alpha$ in normal, sham-operated, HSP, SJF, and fluoxetine groups at weeks I, 2 , and 4 after HSP phase ( $\mathrm{n}=6$ per group). $* P<0.05,{ }^{* *} P<0.01$ vs normal and sham rats; ${ }^{\#} P<0.05,{ }^{\# *} P<0.01$ vs $P P D$ rats; ${ }^{*} P<0.05$ vs I week; ${ }^{\wedge} P<0.05$ vs 2 weeks.

Abbreviations: IL, interleukin; SJF, Shen-Qi-Jie-Yu-Fang; PPD, postpartum depression; HSP, hormone-simulated pregnancy; SEM, standard error of mean. 


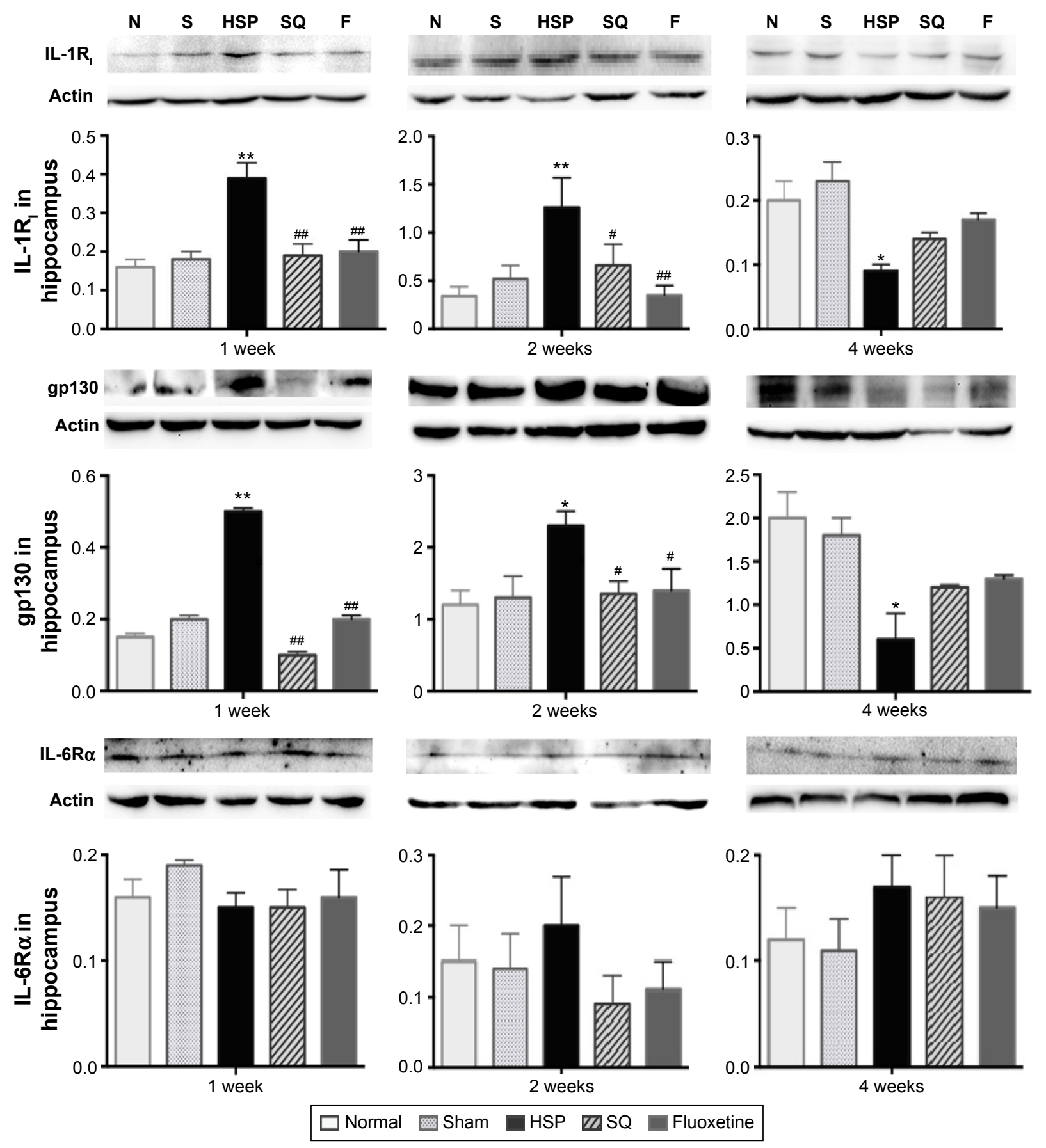

Figure 6 Effect of SJF on protein expression of IL-IR, gP I30, and IL-6R $\alpha$ of PPD rats with HSP withdrawal.

Notes: Protein expression (mean \pm SEM) of IL-IR, gP I 30, and IL-6R $\alpha$ in normal, sham-operated, HSP, SJF, and fluoxetine groups at weeks I, 2, and 4 after HSP phase ( $n=6$ per group). $* * P<0.01, * P<0.05$ vs normal and sham rats; $\# P<0.05, \# P<0.01$ vs $P P D$ rats.

Abbreviations: IL, interleukin; SJF, Shen-Qi-jie-Yu-Fang; PPD, postpartum depression; HSP, hormone-simulated pregnancy; SEM, standard error of mean; N, normal group; $S$, Sham group; F, fluoxetine group.

of gp130 in the HSP group at 4 weeks was lower than that at 1 and 2 weeks ( $t=-4.034$ and $t=-4.261$, respectively; $P<0.01$ ) (Figure 5C). Protein expression of gp130 in the HSP group was also higher than all the other groups at 1 and 2 weeks $(P<0.05)$ and lower than the normal and sham groups at 4 weeks after the start of intervention $(P<0.05)$ (Figure 6).

\section{$\mathrm{CD}^{+} \mathrm{CD} 25^{+} \mathrm{T}_{\text {reg }}$ cells decreased in PPD rats and were increased by SJF and fluoxetine}

The levels of $\mathrm{CD} 4^{+} \mathrm{CD} 25^{+} \mathrm{T}_{\text {reg }}$ cells in the HSP group remained lower than the normal and sham-operated groups at 1 $\left(F_{4,25}=2.965, P<0.05\right)$ and 2 weeks $\left(F_{4,25}=2.927, P<0.05\right)$, and recovered to normal at 4 weeks. The SJF and fluoxetine groups 
had higher levels of $\mathrm{CD}^{+} \mathrm{CD} 25^{+} \mathrm{T}_{\text {reg }}$ cells than the HSP group at 1 and 2 weeks $(P<0.05)$, while the level was lower in the SJF group than the normal and sham groups at 4 weeks $\left(F_{4,25}=2.902\right.$, $P<0.05$ ) (Figure 7A). When all the rats were included in the correlation analysis, $\mathrm{CD} 4^{+} \mathrm{CD} 25^{+} \mathrm{T}_{\text {reg }}$ cells were found to be negatively correlated with levels of IL-1 $\beta(r=0.3479, P=0.0207)$ and IL-6 ( $r=0.3398, P=0.0266)$ (Figure 7B).

\section{Discussion}

In this study, SJF appeared to exert a positive effect on PPD by improving depressive behaviors of HSP-group rats. The most significant finding was that there was a complex change in the levels of proinflammatory cytokines and $\mathrm{CD} 4^{+} \mathrm{CD} 25^{+}$ $\mathrm{T}_{\text {reg }}$ cells in PPD rats, and both SJF and fluoxetine appeared to modulate their balance. In view of the changes in IL-1 $\mathrm{R}_{\mathrm{I}}$ and gp130 in the hippocampi of PPD rats, we suspect that proinflammatory cytokines may act on the brain in PPD by regulating their receptors, and that SJF and fluoxetine can prevent this action.

\section{SJF appears to attenuate depressive behaviors of HSP rats}

The results of our study show that HSP rats had decreased horizontal and vertical movements in the OFT, increased immobility time in the FST, and decreased sucrose intake at 1 , 2 , and 4 weeks after pregnancy was simulated. The OFT is a common measure of exploratory behavior and general activity in rodents, and is used to observe behavior in the rat model of depression. Decreased horizontal and vertical movements in OFT tests in our study indicated low interest and activity, which are the main symptoms of PPD. The FST is an experiment for assaying mood levels in rodents. ${ }^{27}$ Increased immobility time in the FST is an indicator of depression severity. Galea et $\mathrm{a}^{28}$ found significantly increased immobility in the FST at 48 hours after the last injection of sex hormone during the pregnancy period. Our study showed similar results, and further demonstrated long-lasting depression performance in the FST of HSP rats. Sucrose consumption in rats is believed to be a measure of decreased "pleasure", and appears to be significantly decreased in chronic mild stress. ${ }^{29}$ Navarre et $\mathrm{al}^{30}$ found that HSP rats showed significantly less preference than vehicle-control rats for sucrose during the first 3 weeks of the "postpartum" period, which concurs with the results of this study.

We found that SJF and fluoxetine started producing effects on horizontal scores in the OFT at 1 week and increased sucrose consumption at 2 weeks. These results were also in accord with our previous study. ${ }^{31}$ Immobility in the FST was not improved by fluoxetine until 4 weeks, but was improved by SJF at 2 weeks. These results varied slightly from previous studies. For example, Li et a ${ }^{17}$ found immobility time in the FST at 1, 2, and 4 weeks in the SJF and fluoxetine groups was less than the HSP group, while Qu et $\mathrm{al}^{31}$ demonstrated that immobility time after administration of the two drugs was shorter at 2 weeks. As the dosages of the two drugs were the same in these studies, the variation in the results may have been due to operator error when assessing immobility times during the FST. Nevertheless, the
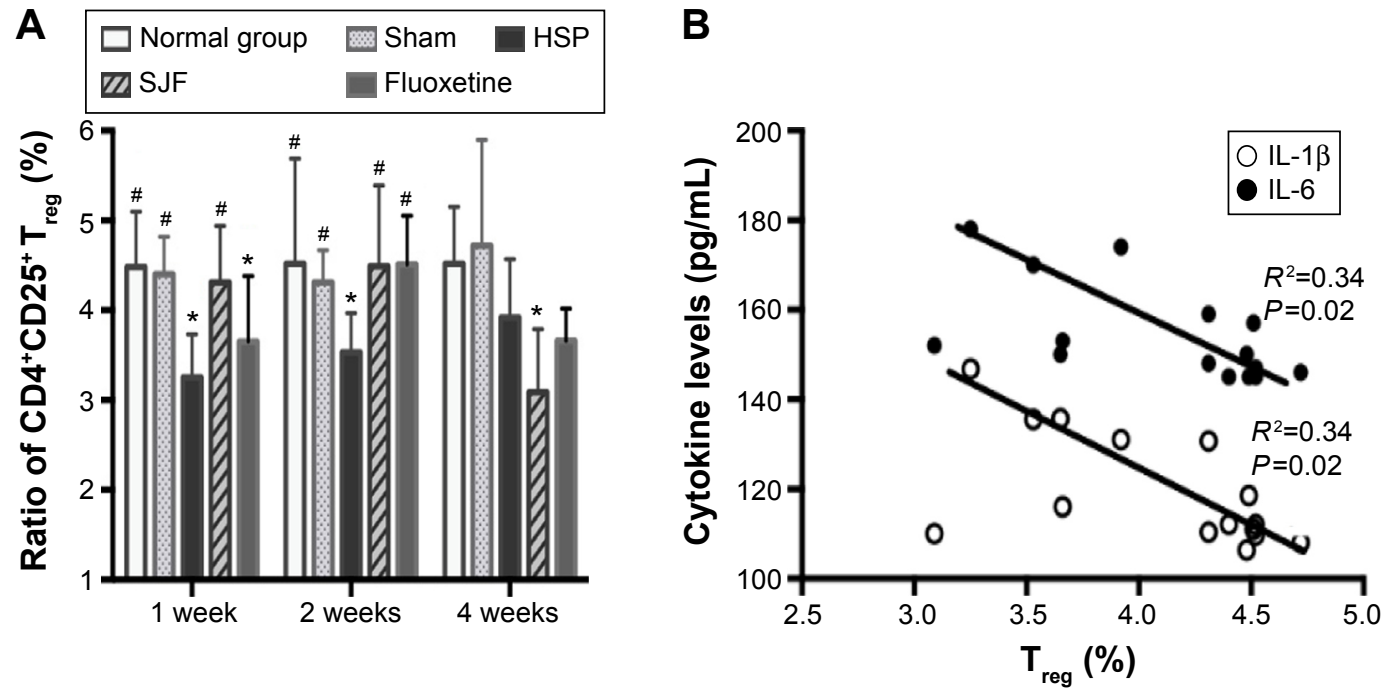

Figure 7 Effect of SJF on ratio of $C D 4^{+} C D 25^{+} T_{\text {reg }}$ cells in $C D 4{ }^{+} C D 25^{+} T$ cells of PPD rats $(\mathbf{A})$; correlation between $T_{\text {reg }}$ cells, serum IL-I $\beta$, and serum IL-6 (B). Notes: Ratio of $C D 4+C D 25^{+} T_{\text {reg }}$ cells (mean \pm SEM) in normal, sham-operated, HSP, SJF, and fluoxetine groups ( $n=6$ per group) at weeks I, 2 , and 4 after HSP phase. $* P<0.05$ vs normal and sham rats; ${ }^{\#}<0.05$ vs $P P D$ rats.

Abbreviations: IL, interleukin; SJF, Shen-Qi-Jie-Yu-Fang; $\mathrm{T}_{\text {reg }}$, regulatory T; PPD, postpartum depression; HSP, hormone-simulated pregnancy; SEM, standard error of mean. 
general trend of the results of these studies appears to show that both SJF and fluoxetine improve behavioral performance of PPD rats.

\section{SJF appears to regulate proinflammatory cytokine changes in PPD}

Proinflammatory cytokines, IL- $1 \beta$ and IL-6, are important interaction mediums between the immune and nervous systems, which are closely linked to depression. Metaanalysis by Howren et a ${ }^{132}$ found that depression and CRP, IL-1 $\beta$, and IL-6 were positively associated in clinical and community samples. Other research has also demonstrated that depressed patients are prone to higher levels of serum IL-1 $\beta$ than healthy individuals, ${ }^{33}$ which appears to be the case in elderly depressed patients as well. ${ }^{34}$ The proinflammatory cytokine IL- 6 can regulate activation of the HPA axis under acute stress situations by exerting its effects on the hypothalamus, ${ }^{35}$ an action that can be enhanced by different stressors. ${ }^{36}$ Furthermore, inflammatory changes in the brain characterized by elevated proinflammatory cytokines in the brain are associated with clinical depression. ${ }^{37}$ In women, elevated IL-1 $\beta$ persisted for at least the first month PP and was found to be associated with symptoms of depression, suggesting that elevated IL-1 $\beta$ early in the PP period may increase the risk of PPD. ${ }^{38}$

In the rat model of PPD, serum IL-6 also remained high in HSP rats compared with normal rats throughout a 4-week observation study; however, somewhat different from IL-6 in our study, serum IL- $1 \beta$ in HSP rats was found to be higher than normal rats at 1 and 2 weeks, but presented a declining trend and was lower than normal rats at 4 weeks.

Zhang et $\mathrm{a}^{39}$ found that such variation in trends between IL-1 $\beta$ and IL-6 existed in pregnant women prior to delivery, as a high level of serum IL-1 $\beta$ was detected in the first trimester, which decreased in the second trimester and increased again late in the third trimester ${ }^{39}$ In comparison, serum IL-6 kept elevating in the second trimester, and peaked in the late third trimester. ${ }^{39}$ Given that the trait of the HSP model in this study mimics gonadal hormone conditions before and after pregnancy, drastic changes in these hormones may contribute to changes in serum cytokines during and after the gestational period.

In our study, we found that the serum levels of IL- $1 \beta$ and IL- 6 can be downregulated by SJF and fluoxetine at 1, 2, and 4 weeks, consistent with previous studies. Meta-analysis by Hannestad et $\mathrm{al}^{40}$ found that SSRI treatment, such as with fluoxetine, showed greater reduction in IL-6 levels than other antidepressants, indicating that SSRIs may specifically diminish levels of IL-1 $\beta$ and IL-6. The mechanism by which
SJF exerts its effects in the brain remains to be explored, and could be related to brain receptors.

\section{SJF appears to prevent proinflammatory cytokines from acting in the hippocampi of PPD rats}

As expected, we found a change in gene and protein expressions of IL-1 $\mathrm{R}_{\mathrm{I}}$ and gp130 in hippocampi of PPD rats. IL-6R, the membrane receptor of IL-6, mediates the central and peripheral effects of IL- $6 .^{41}$ The signal action of IL-6R employs a combination of IL-6, the ligand-binding IL-6R $\alpha$, and the signal transducing $\beta$-chain (gp130). These three components oligomerize to form a complex of at least two of each component, which results in the signaling processes conducted by gp $130 .{ }^{42}$ Maes et $a l^{8}$ found that, in pregnant women, serum concentrations of IL-6R were significantly higher than nonpregnant women at 1 and 3 days after delivery and at the end of pregnancy. As an effective type of IL-1R, $\mathrm{IL}-1 \mathrm{R}_{\mathrm{I}}$ locates to almost all cells, including neurons in the rat brain, where it mainly concentrates in the hippocampus, pituitary gland, and hypothalamus..$^{43}$ Increased expression in the hypothalamus of rats under stress contributes to elevation of plasma adrenocorticotropic hormone ${ }^{44}$ Furthermore, in rodent models, IL-1RA can block IL-1 signaling by combining with IL-1 $\mathrm{R}_{\mathrm{I}}$ to reduce depressive-like behaviors caused by IL- $1 \beta \cdot{ }^{45}$ In total, cytokines appear to be responsible for the occurrence of depression by regulating the activity of their receptors in the brain and the subsequent response. ${ }^{46}$

Therefore, increased gene and protein expression of IL- $1 R_{I}$ in the HSP model at 1 and 2 weeks after HSP withdrawal followed by a decrease at 4 weeks was in accord with the change in serum IL- $1 \beta$ in our study, suggesting that the proinflammatory cytokine IL- $1 \beta$ may be a part of the pathophysiology of PPD by regulating the activity of IL- $1 R_{\mathrm{I}}$ in the brain.

Although IL-6R $\alpha$ did not exhibit a significant increase, the marked changes in gp130 in the hippocampus of HSP rats in this study also demonstrated IL-6 action on the hippocampus in PPD rats. In addition, increased serum IL-1 following increased gp130 and IL-1 $\mathrm{R}_{\mathrm{I}}$ in the rat brain at 1 and 2 weeks showed inflammatory activity, while decreased levels at 4 weeks indicated a suppressive activity of proinflammatory cytokines in the brain.

Meanwhile, SJF and fluoxetine had a similar impact on gene and protein expressions of IL-1 $\mathrm{R}_{\mathrm{I}}$ and gp130 in the hippocampus. By week 1 after HSP withdrawal, SJF had prevented increased gene and protein expressions of IL- $1 \mathrm{R}_{\mathrm{I}}$, while fluoxetine also blunted the expression of IL-1 $\mathrm{R}_{\mathrm{I}}$. 
Compared with the drastic decline in IL-1R $\mathrm{R}_{\mathrm{I}}$ from week 1 to 4 after HSP withdrawal in the HSP group, changes in IL-1 $\mathrm{R}_{\mathrm{I}}$ and gp130 in the SJF and fluoxetine groups seemed mild and closer to changes in the normal group. These results suggest that SJF and fluoxetine can attenuate dysfunction of proinflammatory cytokines by interfering with their receptors at different phases of PPD. Furthermore, changes in T-lymphocyte subsets observed in the HSP model in our previous study indicated a shift from immune activation to immunosuppression, and was synchronized with the activity tendencies of proinflammatory cytokines. Therefore, we suspect an underlying relationship between IL-1 $\beta$, IL-6, and T-lymphocyte subsets in the pathogenesis of PPD.

\section{SJF appears to upregulate decreased CD4 ${ }^{+} \mathrm{CD} 25^{+} \mathrm{T}_{\text {reg }}$ cells in PPD}

In this study, levels of CD $4^{+} \mathrm{CD} 25^{+} \mathrm{T}_{\text {reg }}$ cells were found to be decreased in HSP rats than normal rats at 1 and 2 weeks and recovered to normal at 4 weeks. $\mathrm{CD} 4^{+} \mathrm{CD} 25^{+} \mathrm{T}_{\text {reg }}$ cells are a subset of thymus-derived $\mathrm{CD}^{+}{ }^{+} \mathrm{T}$-cell populations that function to inhibit inappropriate or excessive immune responses and mediate immune tolerance by inhibiting proliferation and production of cytokines via their constitutive expression of the IL-2 receptor $\alpha$-chain (CD25) and the transcription factor Foxp $3 .{ }^{47} \mathrm{~T}_{\text {regs }}$ have been found to exhibit neuroprotective functions as well. For example, in a murine model of human immunodeficiency virus, $\mathrm{T}_{\text {reg }}$ cells attenuated astrogliosis and microglia inflammation by decreasing proinflammatory cytokines and increasing brain-derived neurotrophic factor and glial cell line-derived neurotrophic factor. ${ }^{48} \mathrm{~T}_{\text {reg }}$ cells have also been found to prevent autoreactive $\mathrm{T}$ cells from extenuating effects on stress-induced anxiety-like behaviors. ${ }^{49} \mathrm{Kim}$ et $\mathrm{al}^{12}$ found that numbers of $\mathrm{CD} 4^{+} \mathrm{CD} 25^{+} \mathrm{T}_{\text {reg }}$ cells can be decreased by stress, resulting in decreased 5-HT levels within the hippocampus. Moreover, a decrease in $\mathrm{T}_{\text {reg }}{ }^{-}$ cell population in peripheral blood was found in patients with major depression. ${ }^{50}$ Krause et $\mathrm{al}^{14}$ also found that numbers of $\mathrm{CD} 4{ }^{+} \mathrm{CD} 25^{+} \mathrm{T}_{\text {reg }}$ cells decreased in PPD rats, similar to this study. In addition, single-nucleotide polymorphisms in genes that regulate T-cell development and intracellular signaling (eg, STAT3) were found to be significantly associated with the response to antidepressant medications. ${ }^{51}$ These findings raise the intriguing possibility that depletion of $\mathrm{CD} 4^{+} \mathrm{CD} 25^{+}$ $\mathrm{T}_{\text {reg }}$ cells may not only represent a consequence of PPD but also be an important factor in its cause.

In this study, $\mathrm{CD} 4^{+} \mathrm{CD} 25^{+} \mathrm{T}_{\text {reg }}$ cells were negatively correlated with changes in IL-1 $\beta$ and IL-6. IL-6 was also observed to be upregulated by $\mathrm{CD} 4{ }^{+} \mathrm{CD} 25^{+} \mathrm{T}_{\text {reg }}$-cell depletion in previous studies, ${ }^{12}$ which is consistent with the results in this study. $\mathrm{T}_{\text {regs }}$ can inhibit inflammatory response by release of the inhibitory cytokines IL-10 and TGF $\beta,{ }^{47}$ while low serum IL-10 concentrations have been found to be associated with high levels of IL-6 in patients with major depression. ${ }^{52}$ On the other hand, the proinflammatory cytokine IL- 6 was found to inhibit TGF $\beta$-induced $\mathrm{T}_{\text {reg }}$ differentiation. ${ }^{15}$ Given the potential role of inflammation in depression and the ability of $\mathrm{T}_{\text {regs }}$ to inhibit the inflammatory response by producing anti-inflammatory cytokines, the possibility that $\mathrm{T}_{\text {regs }}$ may exert a protective effect is an interesting consideration. Krause et al ${ }^{14}$ observed that $\mathrm{CD}^{+} \mathrm{CD} 25^{+} \mathrm{T}_{\text {reg }}$ cells were increased in prenatal and postnatal mothers with PPD. Perhaps the increase in $\mathrm{T}_{\text {reg }}$ cells was a protective reaction in response to the body's predepression condition, as PPD was not diagnosed in the participating women. Only depressive symptoms in the PP period were investigated. In our study, decrease in $\mathrm{T}_{\text {regs }}$ at 1 and 2 weeks was consistent with previous studies, suggesting that diminished $\mathrm{T}_{\text {reg }}$ activity may be a pathogenic mechanism of PPD. In addition, recovery of $\mathrm{T}_{\text {regs }}$ that coincided with decreased inflammatory activity at 4 weeks in PPD rats demonstrated this interaction, and thus suppressive immune activity in PPD at 4 weeks.

We also observed that SJF had the ability to increase $\mathrm{T}_{\text {regs }}$ at 1 and 2 weeks, which mimicked the effect of fluoxetine. Interestingly, $\mathrm{T}_{\text {regs }}$ in PPD rats were decreased after 4 weeks of treatment with SJF, similar to changes in serum IL-1 in the SJF group at 4 weeks. Therefore, the effects of SJF appear to be comparable to those of fluoxetine in attenuating $\mathrm{T}_{\text {reg }}$ dysfunction in different phases of PPD, leading to improvement in symptoms. However, the exact mechanism by which SJF achieves these results requires further exploration.

There were limitations to our study. We observed only two representative proinflammatory cytokines, which was likely insufficient for elucidating the complete inflammatory activities that occur with PPD. Furthermore, we selected only 1,2 , and 4 weeks after HSP withdrawal as the three observed time points, but did not make any observations during HSP, and thus may have overlooked inflammatory activities during this period. Finally, the rat model of HSP only mimics the hormonal phenomena of human pregnancy and not the social factors of PPD. Therefore, a novel animal model using PP rats that have undergone long and repeated separation from their newborns may be more appropriate for understanding the complete picture of PPD and how SJF functions to treat it. 


\section{Conclusion}

The results of our study indicate that, at different stages of PPD, dysfunction exists among proinflammatory cytokines and $\mathrm{T}_{\text {regs }}$. SJF and fluoxetine appear to attenuate this dysfunction by regulating the serum concentrations of IL-1 $\beta$ and IL-6, expressions of IL-1 $\mathrm{R}_{\mathrm{I}}$ and gp130 in the hippocampus, and $\mathrm{CD} 4^{+} \mathrm{CD} 25^{+} \mathrm{T}_{\text {reg }}$ cells in peripheral blood. These observations should be investigated further by increasing the number of observed time points and measuring additional pro/antiinflammatory cytokines, cytokine receptors, and T-helper cells. Our findings provide new evidence of the pathophysiology of PPD as related to the inflammatory response system and $\mathrm{T}_{\text {regs }}$, and the immunomodulating function of SJF and fluoxetine in PPD.

\section{Acknowledgments}

This study was supported by the Doctoral Fund of the Ministry of Education of China (20130013130002) and Independent Subject of Beijing University of Chinese Medicine (2015JYB-JSMS140). The authors thank Nissi S Wang, MSc, for developmental editing of the manuscript.

\section{Disclosure}

The authors report no conflicts of interest in this work.

\section{References}

1. Li H, Shen RG, Yang HJ, Zhang W, Ding J. [Effects of social and demographic factors on postpartum depression]. Pract Prev Med. 2009; 16(3):690-692. Chinese

2. Field T. Postpartum depression effects on early interactions, parenting, and safety practices: a review. Infant Behav Dev. 2010;22(1):1-6.

3. Walf AA, Frye CA. A review and update of mechanisms of estrogen in the hippocampus and amygdala for anxiety and depression behavior. Neuropsychopharmacology. 2006;31(6):1097-1111.

4. Jung C, Ho JT, Torpy DJ, et al. A longitudinal study of plasma and urinary cortisol in pregnancy and postpartum. J Clin Endocrinol Metab. 2011;96(5):1533-1540.

5. Chen SJ, Liu YL, Sytwu HK. Immunologic regulation in pregnancy: from mechanism to therapeutic strategy for immunomodulation. Clin Dev Immunol. 2012;2012:258391

6. Jolley SN, Elmore S, Barnard KE, Carr DB. Dysregulation of the hypothalamic-pituitary-adrenal axis in postpartum depression. Biol Res Nurs. 2007;8(3):210-222.

7. Taylor A, Glover V, Marks M, Kammerer M. Diurnal pattern of cortisol output in postnatal depression. Psychoneuroendocrinology. 2009; 34(8):1184-1188.

8. Maes M, Lin AH, Ombelet $\mathrm{W}$, et al. Immune activation in the early puerperium is related to postpartum anxiety and depressive symptoms. Psychoneuroendocrinology. 2000;25(2):121-137.

9. Maes M, Verkerk R, Bonaccorso S, Ombelet W, Bosmans E, Scharpé $\mathrm{S}$. Depressive and anxiety symptoms in the early puerperium are related to increased degradation of tryptophan into kynurenine, a phenomenon which is related to immune activation. Life Sci. 2002; 71(16):1837-1848.

10. Boufidou F, Lambrinoudaki I, Argeitis J, et al. CSF and plasma cytokines at delivery and postpartum mood disturbances. J Affect Disord. 2009; 115(1-2):287-292.
11. Drexhage RC, Hoogenboezem TH, Versnel MA, Berghout A, Nolen WA, Drexhage HA. The activation of monocyte and $T$ cell networks in patients with bipolar disorder. Brain Behav Immun. 2011;25(6): $1206-1213$.

12. Kim S, Lee H, Lee G, et al. CD4+CD25+ regulatory T cell depletion modulates anxiety and depression-like behaviors in mice. PloS One. 2012;7(7):e42054.

13. Qu M, Li JY, Tang QS, et al. [Effects of Treg/Th17 cell balance on postpartum depression rats and cellular immune regulation of shenqi jieyu formula]. China J Tradit Chin Med Pharm. 2015;30(5):1452-1458. Chinese.

14. Krause D, Jobst A, Kirchberg F, et al. Prenatal immunologic predictors of postpartum depressive symptoms: a prospective study for potential diagnostic markers. Eur Arch Psychiatry Clin Neurosci. 2014;264(7): 615-624.

15. Kimura A, Kishimoto T. IL-6: regulator of Treg/Th17 balance. Eur J Immunol. 2010;40(7):1830-1835.

16. Noack M, Miossec $P$. Th17 and regulatory T cell balance in autoimmune and inflammatory diseases. Autoimmun Rev. 2014;13(6):668-677.

17. Li XL, Yang XK, Tang QS, Zhao RZ, Lu K. [Research of influence of shenqijieyu prescription on changes of behavioristics and morphology of brain tissue in rats with postpartum depression]. Beijing $J$ Tradit Chin Med. 2013;32(3):177-179. Chinese.

18. Hou XJ, Tang QS, Yang XK, Li XL, Zhang RZ, Wang X. [Research of influence of shenqi jieyu prescription on changes of monoamine neurotransmitter and metabolite in rats with postpartum depression]. Beijing J Tradit Chin Med. 2013;32(3):182-188. Chinese.

19. Yang XK, Tang QS, Zhu MJ, Lu K, Li XL, Zhao RZ. [Research of influence of shenqi jieyu prescription on changes of neuroendocrine system-related hormones in rats with postpartum depression]. Beijing J Tradit Chin Med. 2013;32(3):188-194. Chinese.

20. Zhao RZ, Yang XK, Tang QS, Li XL, Xu H, Gao YS. [Research of influence of shenqi jieyu prescription on expression and distribution of ER in brain tissue in rats with postpartum depression]. Beijing J Tradit Chin Med. 2013;32(3):195-199. Chinese.

21. Robles TF, Glaser R, Kiecolt-Glaser JK. Out of balance: a new look at chronic stress, depression, and immunity. Curr Dir Psychol Sci. 2005; 14(2):111-115.

22. Jin $\mathrm{L}, \mathrm{Wu} \mathrm{F}$, Li X, et al. Anti-depressant effects of aqueous extract from Acanthopanax senticosus in mice. Phytother Res. 2013;27(12): 1829-1833.

23. Al-Reza SM, Rahman A, Sattar MA, et al. Essential oil composition and antioxidant activities of Curcuma aromatica Salisb. Food Chem Toxicol. 2010;48(6):1757-1760.

24. Kim HG, Lee JS, Choi MK, Han JM, Son CG. Ethanolic extract of astragali radix and salviae radix prohibits oxidative brain injury by psycho-emotional stress in whisker removal rat model. PLoS One. 2014;9(5):e98329.

25. Wang F, Sun JR, Huang MY, et al. Design, synthesis and antiinflammatory evaluation of novel 5-benzylidene-3, 4-dihalo-furan-2-one derivatives. Eur J Med Chem. 2014;72:35-45.

26. Li JX, Feng JM, Wang Y, et al. The B-Raf(V600E) inhibitor dabrafenib selectively inhibits RIP3 and alleviates acetaminophen-induced liver injury. Cell Death Dis. 2014;5:e1278.

27. Lino-de-Oliveira C, de Lima TC, de Pádua Carobrez A. Structure of the rat behaviour in the forced swimming test. Behav Brain Res. 2005; 158(2):243-250.

28. Galea LA, Wide JK, Barr AM. Estradiol alleviates depressive-like symptoms in a novel animal model of post-partum depression. Behav Brain Res. 2001;122(1):1-9.

29. Jayatissa MN, Bisgaard C, Tingström A, Papp M, Wiborg O. Hippocampal cytogenesis correlates to escitalopram-mediated recovery in a chronic mild stress rat model of depression. Neuropsychopharmacology. 2006;31(11):2395-2404.

30. Navarre BM, Laggart JD, Craft RM. Anhedonia in postpartum rats. Physiol Behav. 2010;99(1):59-66. 
31. Qu M, Tang QS, Li XL, et al. Shen-qi-jie-yu-fang has antidepressant effects in a rodent model of postpartum depression by regulating the immune organs and subsets of T lymphocytes. Neuropsychiatr Dis Treat. 2015;11:1523-1540.

32. Howren MB, Lamkin DM, Suls J. Associations of depression with C-reactive protein, IL-1, and IL-6: a meta-analysis. Psychosom Med. 2009;71(2):171-186.

33. Piletz JE, Halaris A, Iqbal O, et al. Pro-inflammatory biomakers [sic] in depression: treatment with venlafaxine. World J Biol Psychiatry. 2009; 10(4):313-323.

34. Popa-Wagner A, Buga AM, Tica AA, Albu CV. Perfusion deficits, inflammation and aging precipitate depressive behaviour. Biogerontology. 2014;15(5):439-448.

35. John CD, Buckingham JC. Cytokines: regulation of the hypothalamopituitary-adrenocortical axis. Curr Opin Pharmacol. 2003;3(1): 78-84.

36. Goshen I, Yirmiya R. Interleukin-1 (IL-1): a central regulator of stress responses. Front Neuroendocrinol. 2009;30(1):30-45.

37. Leonard BE, Myint A. Inflammation and depression: is there a causal connection with dementia? Neurotox Res. 2006;10(2):149-160.

38. Corwin EJ, Johnston N, Pugh L. Symptoms of postpartum depression associated with elevated levels of interleukin-1 beta during the first month postpartum. Biol Res Nurs. 2008;10(2):128-133.

39. Zhang L, Bai H, Wang Z. [Changes of hCG and IL-1 $\beta$, IL- 6 , TNF- $\alpha$ serum level in different phase of pregnancy]. Acta Acad Med CPAF. 2008;10(17):864-867. Chinese.

40. Hannestad J, DellaGioia N, Bloch M. The effect of antidepressant medication treatment on serum levels of inflammatory cytokines: a meta-analysis. Neuropsychopharmacology. 2011;36(12):2452-2459.

41. Yamasaki K, Taga T, Hirata Y, et al. Cloning and expression of the human interleukin-6 (BSF-2/IFN beta 2) receptor. Science. 1988; 241(4867):825-828.
42. Anisman H. Cascading effects of stressors and inflammatory immune system activation: implications for major depressive disorder. J Psychiatr Neurosci. 2009;34(1):4-20.

43. Shaftel SS, Griffen WS, O'Banion MK. The role of interleukin-1 in neuroinflammation and Alzheimer disease: an evolving perspective. J Neuroinflammation. 2008;5:7.

44. Kronfol Z, Remick DG. Cytokines and the brain: implications for clinical psychiatry. Am J Psychiatry. 2000;157(5):683-694.

45. Maes M, Song C, Yirmiya R. Targeting IL-1 in depression. Expert Opin Ther Targets. 2012;16(11):1097-1112.

46. Noto C, Ota VK, Santoro ML, et al. Effects of depression on the cytokine profile in drug naïve first-episode psychosis. Schizophr Res. 2015; 164(1-3):53-58.

47. Workman CJ, Szymczak-Workman AL, Collison LW, Pillai MR, Vignali DA. The development and function of regulatory T cells. Cell Mol Life Sci. 2009;66(16):2603-2622.

48. Liu J, Gong N, Huang X, et al. Neuromodulatory activities of CD4+CD25+ regulatory T cells in a murine model of HIV-1-associated neurodegeneration. J Immunol. 2009;182(6):3855-3865.

49. Cohen H, Ziv Y, Cardon M, et al. Maladaptation to mental stress mitigated by the adaptive immune system via depletion of naturally occurring regulatory CD4+CD25+ cells. J Neurobiol. 2006;66(6):552-563.

50. Li Y, Xiao B, Qiu W, et al. Altered expression of CD4(+)CD25(+) regulatory $\mathrm{T}$ cells and its $5-\mathrm{HT}(1 \mathrm{a})$ receptor in patients with major depression disorder. J Affect Disord. 2010;124(1-2):68-75.

51. Wong ML, Dong C, Maestre-Mesa J, Licinio J. Polymorphisms in inflammation-related genes are associated with susceptibility to major depression and antidepressant response. Mol Psychiatry. 2008; 13(8):800-812.

52. Dhabhar FS, Burke HM, Epel ES, et al. Low serum IL-10 concentrations and loss of regulatory association between IL-6 and IL-10 in adults with major depression. J Psychiatr Res. 2009;43(11):962-969.
Neuropsychiatric Disease and Treatment

\section{Publish your work in this journal}

Neuropsychiatric Disease and Treatment is an international, peerreviewed journal of clinical therapeutics and pharmacology focusing on concise rapid reporting of clinical or pre-clinical studies on a range of neuropsychiatric and neurological disorders. This journal is indexed on PubMed Central, the 'PsycINFO' database and CAS,

\section{Dovepress}

and is the official journal of The International Neuropsychiatric Association (INA). The manuscript management system is completely online and includes a very quick and fair peer-review system, which is all easy to use. Visit http://www.dovepress.com/testimonials.php to read real quotes from published authors. 